\title{
Resident work hour restrictions do not improve patient safety in surgery: a critical appraisal based on 7 years of experience in Switzerland
}

\author{
Adrian P Businger ${ }^{1,2^{*}}$, Urban Laffer ${ }^{3}$ and Reto Kaderli ${ }^{3}$
}

\begin{abstract}
In 2005 the Swiss government implemented new work-hour limitations for all residency programs in Switzerland, including a 50-hour weekly limit. The reduction in the working hours of doctors in training implicate an increase in their rest time and suggest an amelioration of doctors' clinical performance and consequently in patients' outcomes and safety - which was not detectable in a preliminary study at a large referral center in Switzerland. It remains elusive why work-hour restrictions did not improve patient safety. We are well advised to thoroughly examine and eliminate the known adverse effects of reduced work-hours to improve our patients' safety.
\end{abstract}

The two main issues of work-hour restrictions in medicine in Western countries were the improvement of patients' safety and the doctors' working conditions. Preceding the idea and implementation of restricted work hours and regulated work shifts were, exemplarily, the milestone Libby Zion case in 1984, some evidence that brings worsened results in clinical performance and simulated tasks $[1,2]$, the view that overtired and inadequately supervised residents are a dangerous weak point in patient care [3], and the political will to approach the problem of doctors' extensive work hours.

In consequence of this milestone case and based on grand jury recommendations, the New York State Department of Health implemented junior doctors' work hours limitations restricted to 80 hours a week in 1989 and subsequently, the US Accreditation council for Graduate Medical Education implemented nationwide duty-hours standards by July 1, 2003 with some modifications in 2008 [4-6].

In the United Kingdom restrictions on residents' work hours were introduced in 1996 with a progressive reduction in junior doctors' working hours based on the European Working Time Directive [7]. On January 1, 2005 the

\footnotetext{
* Correspondence: adrian.businger@gmx.ch

'Department of Surgery, Regionalspital Emmental AG, Oberburgstrasse 54 Burgdorf $\mathrm{CH}-3400$, Switzerland

${ }^{2}$ Emergency Department, University Hospital Bern, Bern, Switzerland

Full list of author information is available at the end of the article
}

Swiss government implemented new work-hour limitations for all residency programs in Switzerland [8], including a 50-hour weekly limit with a maximum overtime of 2 hours per day and 140 hours per year, respectively, and at least 11 hours of rest between duty periods. Overtime per day may exceed 2 hours during work-free business days or in emergency cases. Daily rest time may be reduced to 9 hours several times a week, as long as the resting time amounts to 12 hours, averaged over 2 weeks.

The reduction in the working hours of doctors in training implicate an increase in their rest time and suggest an amelioration of doctors' clinical performance and consequently in patients' outcomes and safety. This seems very plausible and is furthermore supported by some evidence in standardized tasks in the lab. However, in realworld conditions the anticipated positive effect of reduced working hours on patients' care is not detectable. Therefore, several questions arise: whether the reduction of working hours has been adequately implemented by the departments, how strict the residents' adherence to the restrictions is, and whether residents will use their off-time effectively for recovering; it is well known that work hours are frequently underreported by residents [9]. Two reviews provide compelling evidence that residents are more rested after implementation of work-hour restrictions $[10,11]$. It remains unclear whether the studies are able to show what they intend: Even when methodological weaknesses (frequently single training sites

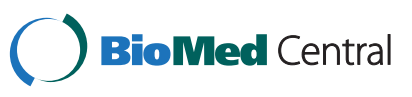


and non-randomized studies) of the included studies might impair the conclusions in two recent systematic reviews, a reduction in working hours to 80 hours has neither shown a clear positive effect on patients' outcomes and safety, nor a clear negative effect of working in shifts, with self-evidently more handovers, transfers and a possible less continuity of patient care; and the systematic reviews have shown only a limited effect on postgraduate medical education $[12,13]$. Ultimately, it cannot be distinguished whether this neutral effect is due to a non-detrimental effect of work hour restriction or is counterbalanced by improved patient care and resident supervision. It remains elusive why work-hour restrictions did not improve patient safety. It seems that there are other influencing factors, such as loss of flexibility or monetary aspects, above all in the United States [14]. The same amount of work should be performed in restricted time while there is insufficient financial support.

The above-mentioned conclusions are all drawn from studies originating in the United States, with a reduction in working hours to 80 hours per week; data from mainland Europe, with reduced hours to less than 56 or 48 hours a week in the United Kingdom, are scarce and contradictory [15-17]. If we assume again that fewer working hours produce more rest time and less fatigue, a more sufficient restriction in work hours from arbitrary 80 hours to 50 hours a week might produce a greater improvement in patients' outcome and safety. In a preliminary study at a large referral center in Switzerland, using the prospective database of the Association for Quality Assurance in Surgery (AQC), the patients' morbidity and mortality following common surgeries, operated by residents before (2001-2004; 1259 patients) and after (2005-2008; 1427 patients) the effects of implementation of work-hour limitations were assessed. The in-hospital mortality (Odds Ratio [OR] 3.61, 95\% Confidence Interval [CI] 1.01-12.93, p $<0.05$ ) and postoperative surgical complication rate (OR $2.76,95 \%$ CI 1.61-4.73, $\mathrm{p}<0.01$ ) were significantly higher after the reform. No significant differences could be found concerning the overall intraoperative $(p=0.61)$ and postoperative medical complication frequencies $(p=0.08)[18]$. This study has several shortcomings, such as retrospective analysis, single-center site study, nonrandomized, and a relatively small " $n$ ". Furthermore, the working hours for doctors-in-training decreased from 52.5 (standard deviation [SD] 0.7) before to 49.7 (SD 0.7 ) hours after the reform. However, an improvement in patient safety has not occurred with the more stringent Swiss work-hour regulation. Work-hour limitations for residents are taken for granted. Studies assessing the effects of work-hour restrictions originating from mainland Europe with greater reductions in the number of work hours compared to those in the United States are essential.

\section{Conclusions}

Considering the different number of work hours for doctors-in-training in the United States and in Switzerland and the failure of improvement in patients' outcome and safety with 80 hours as well as 50 hours, the focus of regulatory agencies and labor unions should change from hours worked to other aspects within work-hour limits (e.g unpaid extracontractual work). Reflecting the critics of decreased professionalism due to less responsibility it might be pathbreaking to qualitatively assess arguments among decision-makers what the main impediments to reduction in working hours are. We are well advised to thoroughly examine and eliminate the known adverse effects of reduced work-hours to improve our patients' safety.

\section{Competing interests}

UL and RK are employed by the Spitalzentrum Biel. UL is the Director of Surgery at Spitalzentrum Biel. The authors declare no other competing interests related to this editorial.

\section{Authors' contributions}

All authors contributed equally to drafting this editorial, and read and approved the final version of the manuscript.

\section{Author details}

${ }^{1}$ Department of Surgery, Regionalspital Emmental AG, Oberburgstrasse 54 Burgdorf CH-3400, Switzerland. 'Emergency Department, University Hospital Bern, Bern, Switzerland. ${ }^{3}$ Department of Surgery, Spitalzentrum Biel, Biel, AG, Switzerland.

Received: 8 June 2012 Accepted: 8 June 2012

Published: 20 July 2012

\section{References}

1. Weinger MB, Ancoli-Israel S: Sleep deprivation and clinical performance. JAMA 2002, 287:955-957.

2. Grantcharov TP, Bardram L, Funch-Jensen P, Rosenberg J: Laparoscopic performance after one night on call in a surgical department: prospective study. BMJ 2001, 323:1222-1223.

3. Landrigan CP, Rothschild JM, Cronin JW, Kaushal R, Burdick E, Katz JT, Lilly CM, Stone PH, Lockley SW, Bates DW, Czeisler CA: Effect of reducing interns' work hours on serious medical errors in intensive care units. $N$ Engl J Med 2004, 351:1838-1848.

4. Report of the New York State Department of Health Ad Hoc Advisory Committee on Emergency Services: Supervision and residents' working conditions. New York: New York State Department of Health; 1987.

5. Accreditation council for Graduate Medical Education: Report of the ACGME work group on resident duty hours. Chicago; 2002. http://www.acgme.org/ acWebsite/dutyHours/dh_index.asp.

6. Iglehart JK: Revisiting duty-hour limits--IOM recommendations for patient safety and resident education. N Engl J Med 2008 2008, 359:2633-263.

7. Department of Health: European Working Time Directive. 2010. http://www.dh. gov.uk/en/Managingyourorganisation/Workforce/

Workforceplanninganddevelopment/Europeanworkingtimedirective/index.htm.

8. Businger A, Guller U, Oertli D: Effect of the 50-hour workweek limitation on training of surgical residents in Switzerland. Arch Surg 2010, 145:558-563.

9. Mache S, Kelm R, Bauer H, Nienhaus A, Klapp BF, Groneberg DA: General and visceral surgery practice in German hospitals: a real-time work analysis on surgeons' work flow. Langenbecks Arch Surg 2010, 395:81-87.

10. Pape HC, Pfeifer R: Restricted duty hours for surgeons and impact on residents quality of life, education, and patient care: a literature review. Patient Saf Surg 2009, 3:3.

11. Fletcher KE, Underwood W 3rd, Davis SQ, Mangrulkar RS, McMahon LF Jr, Saint S: Effects of work hour reduction on residents' lives: a systematic review. JAMA 2005, 294:1088-1100. 
12. Moonesinghe SR, Lowery J, Shahi N, Millen A, Beard JD: Impact of reduction in working hours for doctors in training on postgraduate medical education and patients' outcomes: systematic review. BMJ 2011, 342:d1580. doi:10.1136/bmj.d1580.

13. Jamal MH, Doi SA, Rousseau M, Edwards M, Rao C, Barendregt JJ, Snell L, Meterissian S: Systematic review and meta-analysis of the effect of North American working hours restrictions on mortality and morbidity in surgical patients. Br J Surg 2012, 99:336-344. doi:10.1002/bjs.8657. Epub 2012 Jan 12

14. Nuckols TK, Bhattacharya J, Wolman DM, Ulmer C, Escarce JJ: Cost implications of reduced work hours and workloads for resident physicians. N Engl J Med 2009, 360:2202-2215.

15. Oakely JE, Clewer GJ, Cool WP, Ford DJ: The effect of the EWTD on orthopaedic specialist training. Ann R Coll Surg Engl (Supp) 2005, 87:320-321.

16. Cappuccio FP, Bakewell A, Taggart FM, Ward G, Ji C, Sullivan JP, Edmunds M, Pounder R, Landrigan CP, Lockley SW, Peile E: Warwick EWTD Working Group: Implementing a $48 \mathrm{~h}$ EWTD-compliant rota for junior doctors in the UK does not compromise patients' safety: assessor-blind pilot comparison. QJM 2009, 102:271-282.

17. Collum J, Harrop J, Stokes M, Kendall D: Patient safety and quality of care continue to improve in NHS North West following early implementation of the European Working Time Directive. QJM 2010, 103:929-940.

18. Kaderli R, Businger A, Oesch A, Stefenelli U, Laffer U: Morbidity in surgery: impact of the 50-hour work-week limitation in Switzerland. Swiss Med Wkly 2012, 142. doi:10.4414/smw.2012.13506.

doi:10.1186/1754-9493-6-17

Cite this article as: Businger et al.: Resident work hour restrictions do not improve patient safety in surgery: a critical appraisal based on 7 years of experience in Switzerland. Patient Safety in Surgery 2012 6:17.

\section{Submit your next manuscript to BioMed Central and take full advantage of:}

- Convenient online submission

- Thorough peer review

- No space constraints or color figure charges

- Immediate publication on acceptance

- Inclusion in PubMed, CAS, Scopus and Google Scholar

- Research which is freely available for redistribution 